\title{
Proceeding
}

Supplementary Issue: Summer Conferences of Sports Science. $8^{\text {th }}$ International Workshop and Conference of the International Society of Performance Analysis of Sport (ISPAS), 11-13th of September 2019 (Budapest, Hungary) "Technology meets Practice and Science".

\section{Analysis of the Physical Efficiency Index in football teams and correlation with goal events: A survey of the Italian Serie A Championship}

\author{
LORENZO CANAPINI ${ }^{1}$, CIRO HOSSEINI VARDE'I' ${ }^{1}$ ANTONIO CEJUDO-PALOMO², RICCARDO IZZO1 \\ ${ }^{1}$ Department of Biomolecular Sciences, School of Sport Science, Exercise and Health, University of Urbino Carlo Bo, \\ Urbino, Italy \\ ${ }^{2}$ Department of Physical Activity and Sports, University of Murcia, Spain
}

\begin{abstract}
This paper is centred on the Match Analysis (MA) of football that nowadays is a fundamental tool in the elite level. The MA is the objectively analysis of matches using hardware and software that help the coaching staff to evaluate the performance of the single athlete and the entire team in order to define the Performance Model (PM). Soccer is a nonlinear dynamical system that required a specific mathematical analysis to investigate the relevance of the main key performance indicators (KPIs). Following this issue in 2011, Mirko Marcolini the CEO of K-Sport Universal (Montelabbate, Italy) has registered a patent (IB2010/002593, approved on April 28, 2011 by World Intellectual Property Organization) proposing a new MA approach, based on probability theory, setting as independent variables some KPIs (passes; ball speed; ball trajectory; distance between the holder players, the teammates, the opponents and the fitness ability) provided by the video-tracking and gained using a specific software, in order to analyse the final outcome of a match. From Marcolini formulas is possible to define the technical efficiency index (TEI) and physical efficiency index (PEI), both two percentage parameters (considering as $0 \%$, the worst efficiency and $100 \%$ the maximum efficiency). The aim of this study, was to analyse the TA-PEI during goal actions in order to objectively define if the physical performance is correlated with goal events. Where examined a full season of one team, using video-tracking on 38 games from the 2015/2016 Italian Serie $\mathrm{A}$, and calculated the TA-PEI during goal events for both teams. During this survey, 92 goals were scored, and 184 TA-PEI were collected. For each realization, the TA-PEI was examined, both by the finalizing team and for the team that suffered the goal. On 38 Matches four, two from the first round and two from the second round, ended without goal, end were not considered in the research. The TA-PEI is a resultant variable of different parameters and is certainly a tool that facilitates the task of the match analyst. In this research, attention was focused on the TA-PEI in the goal event, and it establishes the reliability of this parameter. An important update to this study can be the complete analysis of all matches of a championship from different countries or league, in order to receive more different data less affected by causality and errors, and to study if between years or nations there are different or specific trends. Also analysing with the same method, the TA-PEI during all match and not only during goal events can be relevant and useful. In conclusion the TA-PEl is certainly an interesting and valid parameter, from which the results can be used to objectivate and to improve the performance of the team, in an accurate way following the real performance model and help the coaching staff to receive more specific information during crucial moments of matches. Keywords: Match analysis; Key performance indicators; Technical efficiency index; Performance model; Goal actions.
\end{abstract}

Cite this article as:

Canapini, L., Varde'i, C.H., Cejudo-Palomo, A., \& Izzo, R. (2019). Analysis of the Physical Efficiency Index in football teams and correlation with goal events: A survey of the Italian Serie A Championship. Journal of Human Sport and Exercise, 14(5proc), S2390-S2399. doi:https://doi.org/10.14198/ihse.2019.14.Proc5.54

Corresponding author. Department of Biomolecular Sciences, School of Sport Science, Exercise and Health, University of Urbino Carlo Bo, Urbino, Italy.

E-mail: riccardo.izzo@uniurb.it

Supplementary Issue: Summer Conferences of Sports Science. $8^{\text {th }}$ International Workshop and Conference of the International Society of Performance Analysis of Sport (ISPAS), 11-13 th of September 2019 (Budapest, Hungary).

JOURNAL OF HUMAN SPORT \& EXERCISE ISSN 1988-5202

(C) Faculty of Education. University of Alicante

doi:10.14198/jhse.2019.14.Proc5.54

S2390

| 2019 | Proc5 | VOLUME 14

C 2019 University of Alicante 


\section{INTRODUCTION}

The aim of this paper is centred on the Match Analysis (MA) of football that nowadays is a fundamental tool in the elite level. The MA is the objectively analysis of matches using hardware and software that help the coaching staff to evaluate the performance of the single athlete and the entire team in order to define the Performance Model (PM) (Barnes et al., 2014). The match analysis procedures (Barros et al., 2007; Glazier, 2010) can provide a great quantity of information. The aspects to consider in a football competition are physical, technical, tactical and psychological (Belling et al., 2015). The cost of the modern high technologies is decreasing, and now the MA information are available, to an always increasing audience of clubs and specialists (performance analysts, coaches, team managers, and exercise physiologist). The physical demands (external load) was the most studied topic during the last years (Vigne et al., 2010; Castellano et al., 2011). Other important researches investigated the relationship between physical demands and players roles, with the goal to suggest more specific performance models (Gregson et al., 2010, Altavilla et al., 2018). Different countries teams presented differences in physical and technical aspects of match play, cultural differences may contribute to a different PM even in professional soccer leagues. (Di Salvo et al., 2007; Izzo et al., 2019). Find a Connection between parameters of physical performance (objective and quantitative), with technical-tactical indicators were the aim of many studies and more in specific is the goal of modern era of performance analysis (Garcia et al.,2014). Scientists tried to identify a winning profile, but all of those studies were restricted to observing and comparing single factors, in average winning team performed more interceptions; clearances; aerial challenges; and fewer crosses, passes, and dribbles; and when observing two teams of different skill levels, the weaker ones perform more passes and less dribbling (Sarmento et al., 2014). Ball possession was detected greater when losing than when winning or drawing (Lago-Penas et al., 2010). Footballers performed less high-intensity events during winning, in more specific, elite players performed with less high intensity when winning than when losing (Lago-Penas et al., 2011). Given the stochastic and casual nature of a football match, several contradictions are detectable in the available scientific literature that suggest no general consensus about validity of these observations (Rampinini, Coutts, Castagna, Sassi, \& Impellizzeri, 2007). Soccer is a nonlinear dynamical system that required a specific mathematical analysis to investigate the relevance of the main key performance indicators (KPIs). Following this issue in 2011, Mirko Marcolini the CEO of K-Sport Universal (Montelabbate, Italy) has registered a patent (IB2010/002593, approved on April 28, 2011 by World Intellectual Property Organization) proposing a new MA approach, based on probability theory, setting as independent variables some KPIs (passes; ball speed; ball trajectory; distance between the holder players, the teammates, the opponents and the fitness ability) provided by the video-tracking and gained using a specific software, in order to analyse the final outcome of a match. From Marcolini formulas is possible to define the technical efficiency index (TEI) and physical efficiency index (PEI), both two percentage parameters (considering as $0 \%$, the worst efficiency and $100 \%$ the maximum efficiency, defined as follows:

- $\quad$ TEl; derived from three aspects, the playing choices analysis, the Passing analysis and ball possession and the Without ball movements analysis.

- $\quad$ PEl; derived from the external effort performed by players, from various aspects: physical parameters (speed, acceleration, deceleration, mechanical power and metabolic power), physical condition (fatigue and return from injury) and the ability to successfully face a certain event.

In the 2017 (Filetti et al.) analysing 70 matches of 2013-2014 Serie A Championship, tried to evaluate the relevance of the TEI and PEI. Technical parameters involved in TEI seem to have a greater relevance on the final result than the PEI. A higher TEI in a single match produce a higher like hood of winning, in the other hand they found teams able to win showing a low PEI then opponent. These data may help coaches to plan possible interventions, to modify training method and methodology and more in specific to receive useful 
information to read better matches and performance of the own team. The aim of this study was to analyse the team average physical efficiency index (TA-PEI) during the goal actions, evaluate in percentage the capacity of a team to handle every single event during a football match, (the index range, move from 0 worst efficiency to 100 best efficiency. The TA-PEI is the average of values get registered from all the players during matches, it's can be calculated for various time laps: in the Full Match, for the first half, for the second half, for every quarters (15 minutes), for every minute or it can be selected in different technical scenarios (goal actions, defensive actions etc..).

\section{MEANS AND METHODS}

The aim of this study, was to analyse the TA-PEI during goal actions in order to objectively define if the physical performance is correlated with goal events. Where examined a full season of one team, using videotracking on 38 games from the 2015/2016 Italian Serie A, and calculated the TA-PEI during goal events for both teams. During this survey, 92 goals were scored, and 184 TA-PEI were collected. For each realization, the TA-PEI was examined, both by the finalizing team and for the team that suffered the goal. On 38 Matches four, two from the first round and two from the second round, ended without goal, end were not considered in the research.

\section{Data analysis}

Table 1 shows data detected from the 38 matches, the letter $A$ indicate the team we follow for the all season and letter from $B$ to $V$ indicate the others teams that participate to the league during the 2015-2016 Serie $A$, the column result indicate the final result of the match and the columns $1^{\circ} \mathrm{G}, 2^{\circ} \mathrm{G}, 3^{\circ} \mathrm{G}, 4^{\circ} \mathrm{G}, 5^{\circ} \mathrm{G}$ and $6^{\circ} \mathrm{G}$ indicate the TA-PEI value detected during the goal event for both team (home and away). When the team $A$ played in his stadium was indicated with the first letter in the description $(A-B)$ and in the other end when he played away was indicated with the second letter in the description (B-A). This rule, applied in all games, allows the identification of the team that plays at home and the host. A total of 92 goal events are analysed, 48 made in the first and 44 in the second round; therefore 184 TA-PEI were collected, 96 TA-PEI in the first nineteen games and 88 TA-PEI in the last nineteen matches. In particular, 49 finalisations were examined for the home team, 25 in the first round and 24 in second; instead the host team scored 43 goals, 23 in the first and 20 in the second round.

Table 1. Analysed Matches, results and respective TA-PEI values for both teams during goal events.

\begin{tabular}{|c|c|c|c|c|c|c|c|c|}
\hline \multirow{2}{*}{ Match } & \multirow{2}{*}{ Team } & \multirow{2}{*}{ Result } & \multicolumn{6}{|c|}{ Goals and $\%$ TA-PEI } \\
\hline & & & $1^{\circ} \mathrm{G}$ & $2^{\circ} \mathrm{G}$ & $3^{\circ} \mathrm{G}$ & $4^{\circ} \mathrm{G}$ & $5^{\circ} \mathrm{G}$ & $6^{\circ} \mathrm{G}$ \\
\hline 1 & $B-A$ & $2-0$ & $\underline{92}-87$ & $\underline{90}-85$ & & & & \\
\hline 2 & $A-C$ & $2-1$ & $\underline{90}-87$ & $89-\underline{92}$ & $\underline{88}-87$ & & & \\
\hline 3 & $D-A$ & $1-0$ & $\underline{90}-87$ & & & & & \\
\hline 4 & $A-E$ & $3-2$ & $\underline{92}-89$ & $90-\underline{90}$ & $\underline{93}-90$ & $89-\underline{88}$ & $\underline{89}-89$ & \\
\hline 5 & $\mathrm{~F}-\mathrm{A}$ & $2-3$ & $88-\underline{92}$ & $89-\underline{92}$ & $88-\underline{90}$ & $\underline{89}-89$ & $\underline{88}-88$ & \\
\hline 6 & $G-A$ & $1-0$ & $\underline{88}-88$ & & & & & \\
\hline 7 & $A-H$ & $0-4$ & $90-\underline{93}$ & $87-\underline{93}$ & $86-\underline{92}$ & $85-\underline{92}$ & & \\
\hline
\end{tabular}




\begin{tabular}{|c|c|c|c|c|c|c|c|c|}
\hline 8 & I-A & $1-1$ & $87-\underline{91}$ & $\underline{88}-89$ & & & & \\
\hline 9 & $A-L$ & $2-1$ & $\underline{91-89}$ & $87-\underline{86}$ & $\underline{87}-82$ & & & \\
\hline 10 & $A-M$ & $1-0$ & $\underline{90}-87$ & & & & & \\
\hline 11 & $\mathrm{~N}-\mathrm{A}$ & $1-3$ & $90-\underline{93}$ & $89-\underline{89}$ & $89-\underline{90}$ & 89 & & \\
\hline 12 & A-O & $0-0$ & 7 & & & & & \\
\hline 13 & $P-A$ & $1-0$ & $\underline{92}-86$ & & & & & \\
\hline 14 & $A-Q$ & $4-1$ & $\underline{91}-89$ & $\underline{91}-87$ & $\underline{92}-83$ & $\underline{87}-85$ & $86-\underline{87}$ & \\
\hline 15 & $R-A$ & $0-0$ & 7 & & & & & \\
\hline 16 & A-S & $1-1$ & $\underline{90}-87$ & $88-\underline{85}$ & & & & \\
\hline 17 & $\mathrm{~T}-\mathrm{A}$ & $2-4$ & $\underline{89}-88$ & $90-\underline{92}$ & $90-\underline{93}$ & $86-\underline{89}$ & -88 & $85-\underline{90}$ \\
\hline 18 & $A-U$ & $0-1$ & $88-\underline{88}$ & & & & & \\
\hline 19 & $V-A$ & $1-1$ & $\underline{94}-88$ & $91-\underline{92}$ & & & & \\
\hline 20 & $A-B$ & $2-0$ & $\underline{92-90}$ & $90-86$ & & & & \\
\hline 21 & $C-A$ & $2-2$ & $92-\underline{91}$ & $\underline{88}-89$ & $88-\underline{89}$ & $\underline{87}$ & & \\
\hline 22 & $A-D$ & $3-0$ & $\underline{93}-91$ & $\underline{94}-90$ & $\underline{94}-88$ & & & \\
\hline 23 & $E-A$ & $0-2$ & $88-\underline{93}$ & $89-\underline{90}$ & & & & \\
\hline 24 & A-F & $1-1$ & $89-\underline{90}$ & $\underline{90}-88$ & & & & \\
\hline 25 & $A-G$ & $2-1$ & $\underline{89}-89$ & $\underline{89}-82$ & 8 & & & \\
\hline 26 & $\mathrm{H}-\mathrm{A}$ & $1-1$ & $\underline{92}-89$ & $90-\underline{90}$ & & & & \\
\hline 27 & A-I & $1-0$ & $\underline{90}-89$ & & & & & \\
\hline 28 & $L-A$ & $2-0$ & $\underline{90}-91$ & $\underline{88}-87$ & & & & \\
\hline 29 & $\mathrm{M}-\mathrm{A}$ & $0-0$ & 7 & & & & & \\
\hline 30 & $A-N$ & $1-1$ & $89-\underline{89}$ & $\underline{89}-89$ & & & & \\
\hline 31 & $0-A$ & $2-1$ & $90-\underline{90}$ & $\underline{89}-89$ & $\underline{89}-87$ & & & \\
\hline 32 & $A-P$ & $1-2$ & $\underline{90}-90$ & $90-\underline{92}$ & $89-\underline{89}$ & & & \\
\hline 33 & $Q-A$ & $0-1$ & $90-\underline{87}$ & & & & & \\
\hline 34 & $A-R$ & $0-0$ & 1 & 7 & & 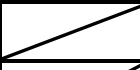 & & \\
\hline 35 & $S-A$ & $2-1$ & $86-\underline{92}$ & $\underline{89}-86$ & $\underline{89}-88$ & & & \\
\hline 36 & $A-T$ & 3-3 & $88-\underline{89}$ & $88-\underline{87}$ & $\underline{88}-88$ & $87-\underline{89}$ & $\underline{87}-88$ & $\underline{88}-84$ \\
\hline
\end{tabular}




\begin{tabular}{|l|l|l|l|l|l|l|}
\hline 37 & $\mathrm{U}-\mathrm{A}$ & $0-1$ & $86-\underline{88}$ & \\
\hline 38 & $\mathrm{~A}-\mathrm{V}$ & $1-3$ & $88-\underline{\underline{95}}$ & $89-\underline{89}$ & $89-\underline{88}$ & $\underline{90}-88$
\end{tabular}

Table 2 shows TA-PEI values during goal actions divided by quarters, considering three TA-PEI cases: TA$P E I>$, when team that make goal show a TA-PEI higher than the other team, TA-PEI =, when the TA-PEI is the same for both team during goal action and TA-PEI <, when the TA-PEI is lower in the team that score the goal then in the one that receive it. In 92 goal actions, 62 were scored with a TA-PEI higher in the team that make goal, 18 with same value of TA-PEI and 12 with a lower value of TA-PEI in the team that make goal. The major finalizations 19 took place during the $4^{\text {th }}$ quarter (45-60); while, only one goal was achieved during the extra time of first half (E.T1). Is important to notice that the quarter with more goals occurred with TA-PEI $<$ was the $5^{\text {th }}(60-75)$.

Table 2. TA-PEI values during goal detected by quarters.

\begin{tabular}{|c|c|c|c|c|c|c|c|c|c|}
\hline \multirow{2}{*}{ TA-PEI } & \multicolumn{7}{|c|}{ Quarters } & \multirow{2}{*}{ Total } \\
\cline { 2 - 11 } & $0^{\prime}-15^{\prime}$ & $15^{\prime}-30^{\prime}$ & $30^{\prime}-45^{\prime}$ & E.T1 & $45^{\prime}-60^{\prime}$ & $60^{\prime}-75^{\prime}$ & $75^{\prime}-90^{\prime}$ & E.T2 & \\
\hline TA-PEI $>$ & 6 & 11 & 9 & 1 & 12 & 9 & 10 & 4 & 62 \\
\hline TA-PEI $=$ & 5 & 1 & 3 & & 5 & 3 & 1 & & 18 \\
\hline TA-PEI $<$ & 1 & 1 & 2 & & 2 & 4 & 2 & & 12 \\
\hline TOT. & 12 & 13 & 14 & 1 & 19 & 16 & 13 & 4 & 92 \\
\hline
\end{tabular}

In the 92 goals examined (figure 1), 49 were scored by home team (53\%), and 43 finalized by the away team (47\%). In particular, the TA-PEI of the finalizing team is higher than the IEFS of the opposing team in 62 goals, which corresponds to $67 \%$ of the total finalizations. In $20 \%$ of the goal events, 18 of the 92 goals, the TA-PEI was same for both teams of the two. While in 12 events in 92 examined, $13 \%$ of the accomplishments, the TA-PEI was higher in the team that have suffered the goal. On the 49 goals performed by the home team, 34 goals, the $37 \%$ of the total analysed, recorded a TA-PEI >. On the 43 goals scored by the away team, 28 were scored with a TA-PEI > the $30 \%$. In total 18 goals were scored with a same value of TA-PEI for both team, 10 goals were scored by the home the $11 \%$ and 8 by the away team the $9 \%$. In the total 12 goals were scored with a TA-PEI < lower than team that suffered goal, 5 were scored at home the $5 \%$ and 7 from the away team in the $8 \%$. In the $92 \mathrm{TA}-\mathrm{PEI}$ registered (Figure 2) the average value for the team that scored goal was of $90 \%$, while the formations that have suffered such goals show an average of $88 \%$. The value of $91 \%$ is the average TA-PEI of the teams in goal, in the 62 goals scored in which the TA-PEl is lower for the teams that suffer the net, the opponents present an average of TA-PEI of $87 \%$. The TA-PEI average of $89 \%$ represent the value of TA-PEI relative to teams that have same value during goal actions.

When the team with lover value make goal the average of TA-PEl is $88 \%$ and for team that suffer goal is $89 \%$. 


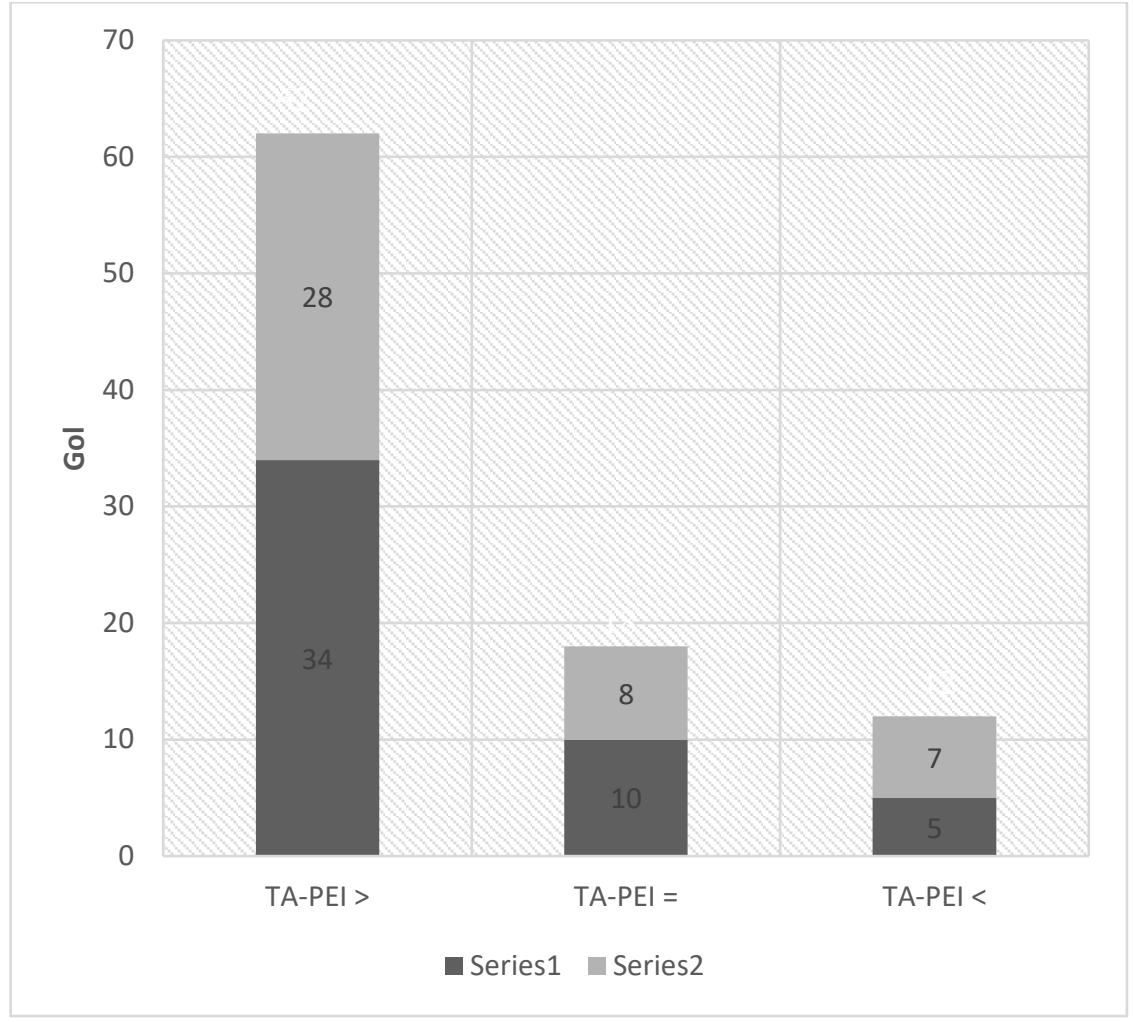

Figure 1. Disposition of goals divided by TA-PEl and Home and Away.

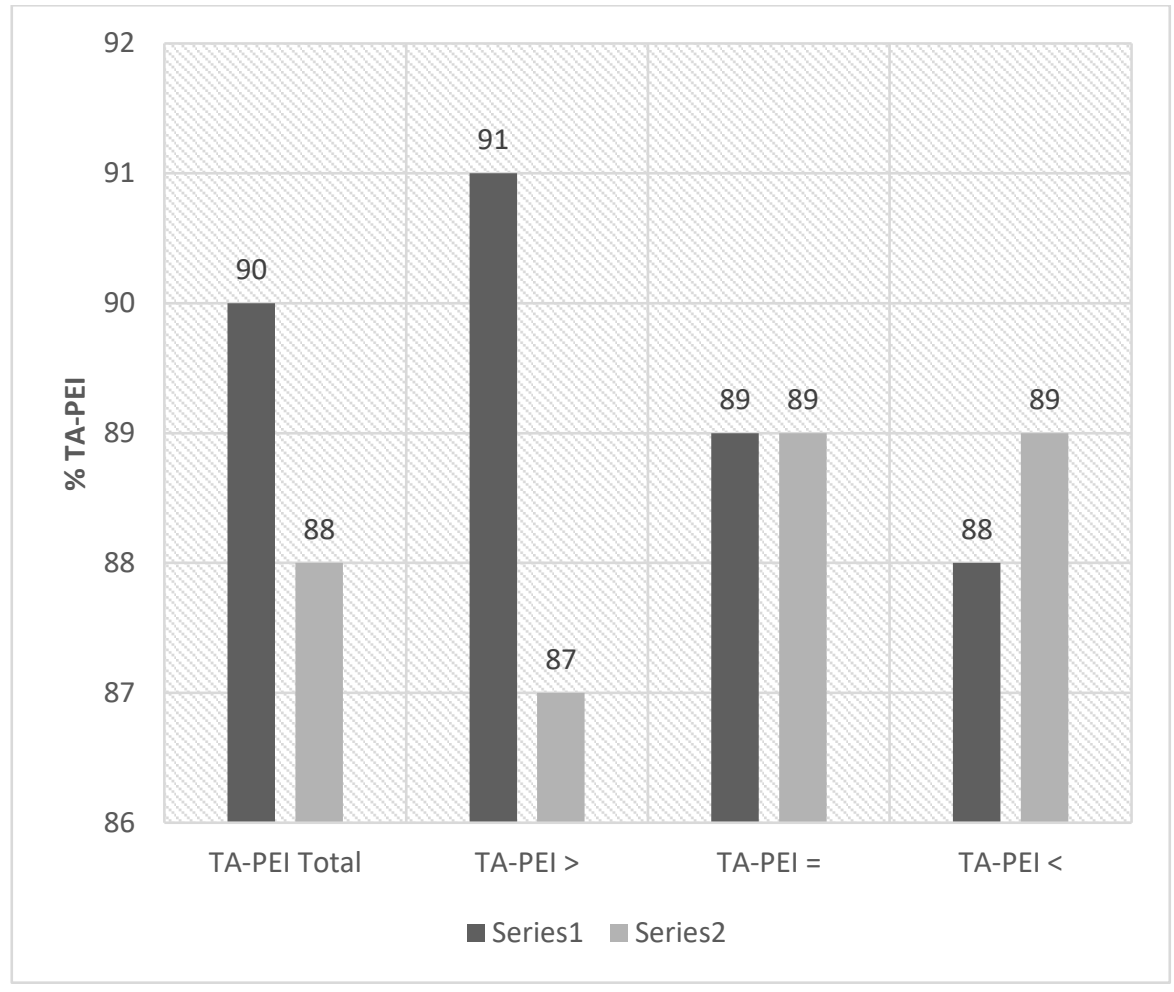

Figure 2. Average Values of TA-PEI during goal actions. 


\section{DISCUSSION}

Analysing the 184 TA-PEI, it is shown that $67 \%$ of the goal events occurred with an TA-PEI > in the team that score goal, this shows how the TA-PEI is a relevant parameter to take into consideration for analyse goals. The other $33 \%$ is divided in: $20 \%$ goal scored with a same value of TA-PEI for both team and $13 \%$ with a TAPEI lower for the team that score goal. In particular, the average of TA-PEI Total, which includes all the goal events examined, for the finalizing teams is equal to $90 \%$, while those who suffer the goals have an average of $88 \%$. Scientific studies show that the teams that play at home are favoured from different points of view. Statistically, home formations finish matches with a score in their favour or in any case, the results are less negative than those played away. Furthermore, the frequency with which the teams play in their own stadium is an important factor for a good performance, as for the players the perception of the spaces is more immediate, since each stadium has different measures of the playing field. Psychologically the support of the fans is significant, many times athletes and coaches have asked the supporters to fill the stadium to support the team, to be encouraged to give the maximum agonistically.

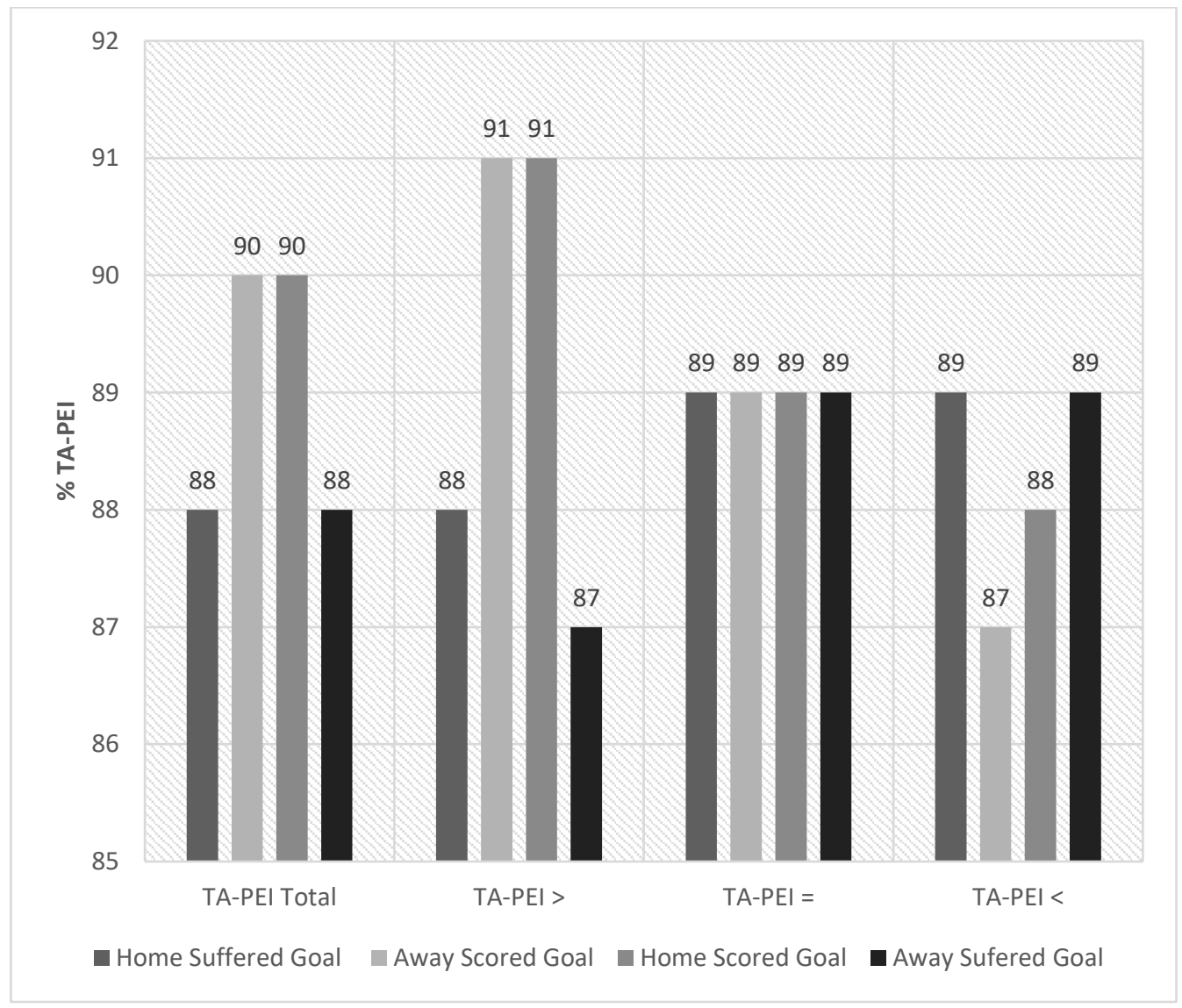

Figure 3. Average value of TA-PEI during Home and Away goal divided by scored or suffered.

It is interesting to note (Figure 3 ) that the TA-PEI of the teams that score at home and away is identical (90\%), and also the TA-PEI of the teams that suffer the goal in their own stadium and away, they have the same value $(88 \%)$, with a lower outcome than those who finalize. This affirms a particular balance of TA-PEI among all the goal events analysed, and don't confirm the assumption that the guest team have to perform a better technical and physical performance to score goal during away matches. Furthermore, by analysing in detail 
the TA-PEl in goal events that took place in the matches, between the "A" team and the three teams ranked in the top three positions, and between Team $A$ and the three relegated teams, at the end of the championship, there are differences. Examining the three best teams in the tournament in the games in which they faced rival the Team A, it is clear that the TA-PEI of the goal events, 16 between facts and suffered for the three clubs, is greater when they play in their own stadium than when compete in the sports facility of Team A. This does not contradict the objectivity of the TA-PEI, but provides an objective assessment of the three formations, that is to say that they are part of those most efficient tournament teams at home. The TA$\mathrm{PEI}$, in the cases of goals made and in the cases of goals conceded, of the three low-ranked teams is less than the three most successful teams and Team A. For example, in situations of finalization against Team $A$, the three strongest teams have an TA-PEI of $92 \%$, while the three least performing formations have an TAPEI of $88 \%$. And again, in the cases of goals against Team A, the three most successful teams recorded an TA-PEI of $90 \%$, and the three less successful teams had an TA-PEI of $87 \%$. Instead for Team A an average of IEFS turns out to be almost identical in the goal events in which it faces the three teams of high ranking and the three teams of low rankings, in fact when Team A take goal the TA-PEI is $88 \%$. A small difference occurs with the TA-PEI of goals scored by Team A, when it scores with the most successful teams it is $91 \%$, and when it achieves with the less successful formations it is $90 \%$. Another concept leads to the investigation, why there have been cases in which, the scorer has a lower TA-PEI than those who suffer goal. A hypothesis is the inattention that the team may have, for example, the defender arrives first on the ball but loses control of the ball a moment later, and the opponent takes advantage of it scoring the goal. The decline in concentration can be caused by multiple factors, including fatigue. From the research, we have that two thirds of the goals scored, in the case in question (TA-PEI <), occurred in the second half, so the psychological tension and the physical effort of the first time accumulated have a substantial value to the fatigue factor.

\section{CONCLUSION}

Basically, the TA-PEI is a useful parameter to understand the phases of matches. In practice, if at a certain minute the TA-PEI is obviously low, it is advisable to study the video of the match of that minute, and then intervene on the part, with the aim of preparing the players in manoeuvring in this situation in future, in both way tactical, technical and physical. The TA-PEI can also be analysed through historical reports, allowing attention to be given to certain game actions. For example, if the TA-PEI is low when the team defends in a given area in a series of matches, this alert can help coaching staff to focus the need to intervene to solve a well-defined problem. Or, if in the first 10 minutes the TA-PEl is low from several games, it is possible that the team enters the field without the right motivation, or the tactics set in the pre-game is not the most appropriate, or the warm-up is performed superficially by the players, etc... The TA-PEI is a useful objective tool, which evaluates the team's performance in each event, which occur throughout the game. This greatly facilitates the work of the staff in assessing the team in matches, and consequently in making certain decisions. Having this precious indicator, it is then the task of the staff to know how to use it. With the advancement of computer technology, the MA has become, in recent years, an integral part, and therefore fundamental, in many sports, especially at a high level. The data that can be obtained through the MA are quantitatively considerable, and this is why the figure of the analyst match is absolutely not to be underestimated. The analyst match is one who is able to identify the parameter, or relatively few parameters, that are relevant in order to improve the performance of the players and the team. The TA-PEI is a resultant variable of different parameters and is certainly a tool that facilitates the task of the match analyst. In this research, attention was focused on the TA-PEI in the goal event, and it establishes the reliability of this parameter. An important update to this study can be the complete analysis of all matches of a championship from different countries or league, in order to receive more different data less affected by causality and errors, and to study if between years or nations there are different or specific trends. Also analysing with the same 
method, the TA-PEI during all match and not only during goal events can be relevant and useful. In conclusion the TA-PEl is certainly an interesting and valid parameter, from which the results can be used to objectivate and to improve the performance of the team, in an accurate way following the real performance model and help the coaching staff to receive more specific information during crucial moments of matches.

\section{REFERENCES}

Barnes C., Archer D. T., Hogg B., Bush M. and Bradley P. S. (2014). The evolution of physical and technical performance parameters in the English premier league, International Journal of Sports Medicine, ISSN 0172-4622. https://doi.org/10.1055/s-0034-1375695

Altavilla, G., Mazzeo, F., D'Elia, F. and Raiola, G. (20180. Physical commitment and specific work for each role in an elite soccer team, Journal of Physical Education and Sport, 18 (2), 570-574.

Barros, R., Misuta, M., Menezes, R., Figueroa, P., Moura, F., Cunha, S., and Leite, N. (2007). Analysis of the distances covered by Erst division Brazilian soccer players obtained with an automatic tracking method. Journal of Sports Science and Medicine, 6(2), 233-242.

Castellano, J., Blanco-Villasen A.and Ivarez, D. (2011). Contextual variables and time-motion analysis in soccer. International Journal of Sports Medicine, 32(6), 415-421. https://doi.org/10.1055/s-00311271771

Di Salvo, V., Baron, R., Gonza' lez-Haro, C., Gormasz, C., Pigozzi, F. and Bachl, N. (2007). Sprinting analysis of elite soccer players during European Champions League and UEFA Cup matches. Journal of Sports Science, 28(14), 1489-1494. https://doi.org/10.1080/02640414.2010.521166

Filetti, C., Ruscello, B., D'Ottavio, S., and Fanelli, V. (2017). Relationships among Technical, Tactical, Physical Parameters and Final Outcomes in Elite Soccer Matches as Analyzed by a Semiautomatic Video Tracking System. Perceptual and Motor Skills, 124(3) 601-62. https://doi.org/10.1177/0031512517692904

Garcia, J. D., Roma' n, I. R., Calleja-Gonza' lez, J., and Dellal, A. (2014). Quantificationand analysis of offensive situations in different formats of sided games in soccer. Journal of Human Kinetics, 30(44), 193-201. https://doi.org/10.2478/hukin-2014-0125

Glazier, P.S. (2010). Game, set and match? Substantive issues and future directions in performance analysis. Journal of Sports Medicine, 40(8), 626-634. https://doi.org/10.2165/11534970-00000000000000

Gregson, W., Drust, B., Atkinson, G., and Di Salvo, V. (2010). Match-to-match variability of high-speed activities in Premier League Soccer. International Journal of Sports Medicine, 31(4), 237-242. https://doi.org/10.1055/s-0030-1247546

Izzo, R., Hosseini Varde'l C., Raiola, G., and Santinelli, F. (2019). Player Performance Model, comparison between youth professional (U-21) and professional first team football players: Different external load or not? Supplementary Issue: Spring Conferences of Sports Science. Costa Blanca Sports Science Events, 14-15 June 2019. Alicante, Spain. https://doi.org/10.14198/ihse.2019.14.proc4.61

Lago-Penas, C. and Dellal, A. (2010). Ball possession strategies in elite soccer according to the evolution of the match-score: The influence of situational variables. Journal of Human Kinetics, 25, 93-100. https://doi.org/10.2478/v10078-010-0036-z

Lago-Penas, C., Lago-Ballesteros, J. and Rey, E. (2011). Differences in performance indicators between winning and losing teams in the UEFA Champions League. Journal of Human Kinetics, 27, 135-146. https://doi.org/10.2478/v10078-011-0011-3 
Rampinini, E., Coutts, A., Castagna, C., Sassi, R. and Impellizzeri, F. (2007). Variation in top level soccer match performance. International Journal of Sports Medicine, 28(12), 1018-1024. https://doi.org/10.1055/s-2007-965158

Sarmento, H., Marcelino, R., Teresa, A. M., Campanic,o, J., Matos, N., and Leitao, J. C. (2014). Match analysis in football: A systematic review. Journal of Sports Sciences, 32(20), 1831-1843. https://doi.org/10.1080/02640414.2014.898852

Vigne, G., Gaudino, C., Rogowski, I., Alloatti, G., and Hautier, C. (2010). Activity proEle in Elite Italian Soccer Team. International Journal of Sports Medicine, 31(5), 304-310. https://doi.org/10.1055/s$\underline{0030-1248320}$ 